\title{
Impact of the oxidative and enzymatic metals in degenerated intervertebral disc disease
}

\author{
Mikołaj Dąbrowski ${ }^{1, A, D \oplus}$, Anetta Zioła-Frankowska ${ }^{2, A-C \oplus}$, Janusz Adamek ${ }^{3, B \oplus}$, \\ Marcin Frankowski ${ }^{4, C, E-F}{ }^{\oplus}$, Jacek Kaczmarczyk ${ }^{5, E}{ }^{\oplus}$, Łukasz Kubaszewski ${ }^{1, A-B, D-E \odot ~}$ \\ ${ }^{1}$ Department of Spine Orthopedics and Biomechanics, W. Dega University Hospital, University of Medical Sciences, \\ Poznan, Poland \\ ${ }^{2}$ Faculty of Chemistry, Department of Analytical Chemistry, Adam Mickiewicz University Poznan, Poland \\ ${ }^{3}$ Provincial Hospital of Alfred Sokołowski, Złotów, Poland \\ ${ }^{4}$ Faculty of Chemistry, Department of Analytical and Environmental Chemistry, Adam Mickiewicz University, Poznan, \\ Poland \\ ${ }^{5}$ University of Medical Sciences, Poznan, Poland \\ $A$ - Research concept and design, B - Collection and/or assembly of data, C - Data analysis and interpretation, \\ $D$ - Writing the article, E-Critical revision of the article, $F$ - Final approval of article
}

Dąbrowski M, Zioła-Frankowska A, Adamek J, Frankowski M, Kaczmarczyk J, Kubaszewski Ł. Impact of the oxidative and enzymatic metals in degenerated intervertebral disc disease Ann Agric Environ Med. 2021; 28(3): 491-501. doi: 10.26444/aaem/126178

\begin{abstract}
Introduction. The degenerative process of the intervertebral disc is a heterogeneous process that may exist in two forms, and involves dominant degenerative changes within the nucleus pulposus and the annulus fibrosus. In degenerative disc disease, the oxidative stress factor can play an important role.

Objective. The aim of research was to present a new approach to understanding the role of the analyzed elements in the process of degeneration of the intervertebral disc.

Materials and method. Selected elements from oxidative groups ( $F e, \mathrm{Zn}, \mathrm{Mo}, \mathrm{As}, \mathrm{Se}$ ), associated with enzymatic processes (Fe, Mo, Se, Zn, Ag, As, Bi), metals (Fe, Zn, Mo, Li) and metalloids (As, Bi) and their content was analyzed depending on the changes in the radiological images of the intervertebral disc. Elemental content analysis was performed by Inductively Coupled Plasma Mass Spectrometry analytical technique.

Results. The similarity between Fe and Se has been demonstrated during different stages of the analysis of groups of patients with degenerative disc disease. There was a negative correlation between Li and degenerative disc disease. The results also suggest that Fe and $\mathrm{Ag}$ are involved in degenerative changes within the intervertebral disc. A potential relationship between $\mathrm{As} / \mathrm{Bi}$ and $\mathrm{Fe} / \mathrm{Mo}$ in the degeneration of the intervertebral disc was demonstrated.

Conclusions. Only some of the correlations can be explained by the metabolism of morphological elements of the intervertebral disc. The relationships indicate new directions for further studies on the degeneration process of the intervertebral disc. The presented study may reflect metabolic changes in the intervertebral disc and adjacent structures in response to the progressive degenerative process.
\end{abstract}

Key words

metals, oxidative elements, intervertebral disc degeneration process, enzymatic elements, ICP-MS

\section{INTRODUCTION}

The incidence of degenerative changes increases with age. In most cases, degenerative disease of the spine begins within an intervertebral disc (IVD). Degeneration of the IVD is a heterogeneous process that may exist in two forms, and involves dominant degenerative changes within the nucleus pulposus and the annulus fibrosus.

The IVD is one of the few structures in the vertebrate organism that is devoid of direct vascularization and innervation [1]. Decreased availability of both oxygen and nutrients can result in impairment of the regenerative potential within the nucleus pulposus. In addition, an increase in stiffness and bone remodeling within the end plate will result in an increase in the strength of the juncture of the bone and chondral end plate, leading to degenerative changes. In osteoarthritis, the disturbance observed in perfusion

Address for correspondence: Mikołaj Dąbrowski, University of Medical Sciences, 28 Czerwca 1956, 135/147, 61-545, Poznan, Poland

E-mail: mdabrowski@ump.edu.pl

Received: 03.06.2020; accepted: 06.08.2020; first published: 03.09.2020 through the cartilage end plate increases the retention of lactic acid, resulting in lower $\mathrm{pH}[2,3]$. Reduction in the water content within the nucleus pulposus, observed with an increase in age, leads to pathological stresses within the fibrous annulus, causing damage to itself, which may result in its rupture and the formation of a hernia of the nucleus pulposus. The persistence of non-physiological loads within the IVD leads to the formation of osteophytes within the vertebral body edges. In advanced degenerative disc disease (DDD), osteophytes can connect to adjacent vertebrae, leading to spontaneous spinal fusion.

In the degenerative disc process, inflammatory changes were observed within the extracellular matrix. Inflammatory mediators released within the nucleus pulposus can lead to elevated plasma concentrations of catabolic enzymes, such as matrix metallopeptidases (MMPs), aggrecanase, and catabolic enzymes aggrecan (a disintegrin and metalloproteinase with thrombospondin motifs, ADAMTS) [4].

Oxidative elements. The following elements show positive oxidative potential: As, Mo, Fe, Zn and Se. Compounds with 
redox potential may play a significant role in the deactivation of free oxidants within the cell. The powerful antioxidant role of the Fe ion has been proven. In DDD, the oxidative stress factor can play an important role [5].

Enzymatic elements. It is not entirely possible to clearly define the elements that are a component of enzymes in the metabolism of human cells. Some elements, such as Ag, As, or $\mathrm{Bi}$, seem to have no significant biological significance, whereas others, such as Fe, Se, Mo, or $\mathrm{Zn}$, are found in enzymes or other protein compounds. Others, such as Li, are not important components of the tested compounds and structures within the cell, even though they are recognized as essential elements

Metals and metalloids. The elements chosen for the analysis were different in terms of biological significance and chemical and biological characteristics in order to evaluate mutual changes and relationships. For the chemical analysis, elements from oxidative groups associated with enzymatic processes, metals, and metalloids were selected. The group of studied elements included Ag, As, Bi, Fe, Li, Mo, Se, and $\mathrm{Zn}$. The selected elements were divided into the following groups: metals (Fe, Zn, Mo, Li), metalloids (As, Bi), enzymatic elements (Fe, Mo, Se, Zn), potentially enzymatic inert elements (Ag, As, Bi), oxidative elements (Fe, $\mathrm{Zn}, \mathrm{Mo}$ ), and low oxidation potential elements (As, Se). As a criterion for the degree of severity of degenerative changes, a radiological analysis based on X-ray and magnetic resonance studies was adopted.

\section{OBJECTIVE}

The aim of the study was to present a new approach to understanding the role of the analyzed elements in the process of degeneration of the IVD. The study may also reflect metabolic changes in the IVD and adjacent structures in response to the progressive degenerative process. Moreover, the study could be the basis for determining whether the concentration of trace elements in the IVD tissue can be an indicator of metabolic changes in connection with the degenerative process.

\section{MATERIALS AND METHOD}

Patients. The study consisted of 58 samples from 53 patients (27 women and 26 men), aged 23-72 years (mean age $45.8 \pm 11.9$ ), with symptomatic osteoarthritis of the IVD in the lumbar spine. Five patients (three women and two men) had multi-level degenerative changes, and material from two spine segments was collected.

Qualification for the surgery involved presentation of the clinical symptoms of osteoarthritis of the spine in the form of local pain, radicular pain, and other neurological disorders (one and multi-level isolated DDD, stenosis of the spinal canal due to degenerative disease, and degenerative scoliosis). Before qualification for surgical treatment, the patients underwent at least six months of conservative treatment in the form of physiotherapy and pharmacotherapy. The most common surgical procedure included segments L4/L5 (39.7\%) and L5/S1 (34.5\%). Fourth and third degree of IVD dehydration was assessed on the Pfirrmann scale ( $48.3 \%$ and $24.1 \%$, respectively). In $46.6 \%$ of the cases, no changes in the bone tissue adjacent to the end plate were observed.

On the Modic scale, second and first degree $(22.4 \%$ and $17.2 \%$, respectively) dominated. No instability of spine was observed in most cases in the group (55.2\%). Osteophytes were observed in stage I (29.3\%) and stage II (15.5\%). The dominant type of deformation within the annulus fibrosus was protrusion (75.9\%).

IVD tissue samples were collected during discectomy and interbody fusion of the spine and perpendicular stabilization of the lumbar spine. In all procedures, removal of tissue was performed, which is an integral part of the procedure that does not cause additional load or damage to the patient.

Chemical analysis. IVD samples were taken intraoperatively during discectomy or intervertebral fusion of the spine and basal stabilization in the lumbar region of the spine. In all treatments, removal of the examined tissue was an integral part of the procedure and did not cause additional burden or damage to the patient. After the surgical procedure, the IVD samples were frozen at $-20^{\circ} \mathrm{C}$ in polyethylene containers. The frozen biological samples were then freeze-dried using a Lyovac lyophilizer GT2e (Steris, Germany) for 24 hours. After drying, the sample was weighed and nitric acid (Suprapur ${ }^{\oplus}$, Merck) was added to obtain a dilution factor of 10 . The samples with nitric acid were left to stand for eight hours to slow the mineralization process. The mineralization was performed by closed-vessel microwave-assisted acid digestion in an Anton Paar Multiwave Pro microwave oven equipped with an 8NXF 100 rotor. The post-mineralization extract of the IVD samples was clear, without visible sediment or fat residues. The extract was placed in a flask which was filled with deionized water from a Milli-Q Direct 8 Water Purification System (Merck, Millipore). The accuracy of the performed procedure was checked by analysis of two standard reference materials (Bone Ash 1400 and Bone Meal 1486; NIST-National Institute of Standard and Technology) by ICP-MS (Inductively Coupled Plasma Mass Spectrometry) analytical technique. The obtained recoveries varied from $97.5 \%-103 \%$. The concentrations of Fe, $\mathrm{Zn}, \mathrm{Mo}, \mathrm{Li}, \mathrm{As}, \mathrm{Bi}, \mathrm{Ag}$, and Se was determined by ICP-MS analytical technique (ICPMS 2030 spectrometer Shimadzu, Japan). For calibration, the ICP IV multi-element standard was used (Merck), as well as single standards for ICP-MS of As, Se, and Mo (Merck). During analysis by ICP-MS analytical technique Sc, Rh, Tb, and Ge (Sigma-Aldrich) internal standards in Suprapur ${ }^{\oplus} 1 \%$ $\mathrm{HNO}_{3}$ were used.

Radiographic assessment. The degenerative process in MRI were classified by the five-point Pfirrmann scale. The classification is based on dependent T2 images. Spinal instability was assessed as the ratio of displacement of the depth of vertebral bodies in the sagittal plane. In the literature, it was found that under physiological conditions, dislocation within the segment between vertebrae L1 and L5 was around $5.4 \pm 2 \%$, and within the segment between vertebrae L5 and S1 it was around $3.9 \pm 4.5 \%$. Values exceeding these values can be regarded as radiological evidence of instability. The observed degenerative disc changes were classified according to the 4-stage Modic scale. In DDD, osteophytes are considered as a symptom associated with the advanced stages of the degenerative process. 
Statistical and chemometrics analysis. Statistica 12.0 (StatSoft) software was used in the analysis. To determine compliance with the expected normal distribution of results, a Shapiro-Wilk test ( $\mathrm{p}<0.05)$ was used. The Spearman's rank correlation between trace elements occurring in the materials and the correlation between the different studied metals in the IVD was determined. Principal Component Analysis (PCA) was used to calculate significant explanatory factor scores for each element, using all physical and chemical variables independently.

Ethics statement. Permission to use IVD samples in the study was granted by the Bioethical Committee of the University of Medical Sciences in Poznan (Poland) (Permit No. 391/16). All patients involved provided written informed consent prior to participation.

\section{RESULTS}

Elements with different biological and chemical properties were selected for analysis to assess mutual correlations. As a criterion for the degree of severity of degenerative changes, radiological analysis based on X-ray diagnostic studies and magnetic resonance imaging was adopted. These studies may reflect metabolic changes in the IVD and adjacent structures in response to the progressive degenerative process. This analysis could be the basis for determining whether the concentration of trace elements in the IVD tissue could be considered an indicator of the metabolic changes in connection with the degenerative process.

Osteophytes. There was no correlation between the elements and the osteophytes. In the analysis there was a negative correlation between Fe and As, and a positive correlation between $\mathrm{Zn}$ and $\mathrm{Bi}$ in patients with osteophytes (Tab. 1).

There were no significant correlations between the frequency of osteophytes and metal content. Chemometric analysis revealed the presence of all biologically significant

Table 1. Spearman correlation coefficients for metals found in the IVD by presence of osteophytes in the X-ray image

\begin{tabular}{|c|c|c|c|c|c|c|c|c|}
\hline & $\mathrm{Ag}$ & As & $\mathrm{Bi}$ & $\mathrm{Fe}$ & $\mathrm{Li}$ & Mo & $\mathrm{Se}$ & $\mathrm{Zn}$ \\
\hline & \multicolumn{8}{|c|}{ without osteophytes } \\
\hline $\mathrm{Ag}$ & $x$ & 0.15 & 0.04 & -0.08 & -0.01 & 0.10 & -0.07 & 0.21 \\
\hline As & 0.41 & $x$ & $0.41^{*}$ & -0.10 & 0.23 & $0.29 *$ & 0.21 & 0.19 \\
\hline $\mathrm{Bi}$ & -0.18 & 0.43 & $x$ & 0.02 & 0.08 & 0.16 & $-0.42^{*}$ & 0.23 \\
\hline $\mathrm{Fe}$ & -0.52 & $-0.63^{*}$ & -0.08 & $x$ & 0.14 & -0.17 & 0.01 & 0.09 \\
\hline $\mathrm{Li}$ & 0.44 & 0.47 & -0.31 & -0.41 & $x$ & 0.06 & -0.10 & 0.24 \\
\hline Mo & -0.09 & 0.08 & 0.07 & -0.16 & -0.09 & $x$ & -0.15 & 0.16 \\
\hline Se & -0.38 & -0.27 & -0.21 & 0.46 & -0.42 & -0.13 & $x$ & -0.20 \\
\hline \multirow[t]{2}{*}{$\mathrm{Zn}$} & -0.22 & 0.45 & $0.82^{*}$ & -0.32 & 0.07 & -0.12 & -0.54 & $x$ \\
\hline & \multicolumn{8}{|c|}{ osteophytes } \\
\hline
\end{tabular}

* statistically significant

elements as the first factor describing the variability in the group of patients with osteophytes. The non-enzymatic elements content (As and $\mathrm{Bi}$ ) described as first factor in the group of patients without osteophytes (Fig. 1). In clustering analysis, a higher similarity between $\mathrm{Bi}$ and As content was showed in the osteophytes group (Fig. 2).
Instability. The obtained results do not directly indicate the influence of the concentration of individual elements on the signs of instability within the surgical motion segment. In the case of radiological symptoms of instability, a positive correlation was observed between $\mathrm{Bi}, \mathrm{As}$, and $\mathrm{Zn}$. A negative correlation was observed between $\mathrm{Fe}$ and $\mathrm{Ag}$, as well as between Se and Bi (Table 2).

Table 2. Spearman correlation coefficients for metals found in the IVD with the division into the presence of instability in the X-ray image

\begin{tabular}{lcccccccc}
\hline & $\mathrm{Ag}$ & $\mathrm{As}$ & $\mathrm{Bi}$ & $\mathrm{Fe}$ & $\mathrm{Li}$ & $\mathrm{Mo}$ & $\mathrm{Se}$ & $\mathrm{Zn}$ \\
\hline $\mathrm{Ag}$ & $\mathrm{X}$ & -0.07 & -0.24 & 0.07 & -0.05 & -0.08 & -0.03 & 0.09 \\
\hline $\mathrm{As}$ & 0.27 & $\mathrm{X}$ & 0.30 & -0.06 & 0.19 & 0.24 & 0.20 & 0.09 \\
\hline $\mathrm{Bi}$ & 0.19 & $0.46^{*}$ & $\mathrm{X}$ & 0.00 & -0.01 & 0.33 & -0.27 & 0.08 \\
\hline $\mathrm{Fe}$ & $-0.46^{*}$ & -0.30 & -0.01 & $\mathrm{X}$ & 0.35 & -0.22 & 0.16 & 0.11 \\
\hline $\mathrm{Li}$ & 0.14 & 0.36 & 0.14 & -0.24 & $\mathrm{X}$ & -0.07 & -0.17 & -0.03 \\
\hline $\mathrm{Mo}$ & 0.18 & 0.32 & 0.08 & -0.12 & 0.16 & $\mathrm{X}$ & -0.27 & 0.10 \\
\hline $\mathrm{Se}$ & -0.18 & 0.14 & $-0.54^{*}$ & 0.00 & -0.18 & 0.00 & $\mathrm{X}$ & 0.00 \\
\hline $\mathrm{Zn}$ & 0.23 & 0.31 & $0.47^{*}$ & -0.11 & $0.41^{*}$ & 0.23 & $-0.54^{*}$ & $\mathrm{X}$ \\
\hline & & & \multicolumn{7}{c}{ instability } & & &
\end{tabular}

* statistically significant

In the chemometric analysis of patients with instability, the first factor included the contents of $\mathrm{As}, \mathrm{Bi}, \mathrm{Li}$, and $\mathrm{Zn}$ (metabolic elements), while the second factor was dominated by Ag, Fe, and Mo metals (Fig. 3). In clustering analysis, the greatest similarity in the group with instability was between Bi and Li (Fig. 4).

Type of deformation of the annulus fibrosus. Analysis showed that the concentrations of the individual elements did not differ depending on the type of disc herniation. Correlation analysis demonstrated a positive correlation between the concentrations of $\mathrm{As}$ and $\mathrm{Bi}$, and a negative correlation between the concentrations of $\mathrm{Bi}$ and $\mathrm{Se}$. In the case of extrusion, a positive correlation was demonstrated between $\mathrm{Li}$ and $\mathrm{As}$, and between $\mathrm{Bi}$ and $\mathrm{As}$, as well as a negative correlation between $\mathrm{Bi}$ and $\mathrm{Se}$ (Tab. 3).

In the PCA in the case of protrusion, the first factor was the As and Bi content, and as the second factor, by Li and $\mathrm{Zn}$. In the case of extrusion, the first factor included the enzymatic elements and a pair of non-enzymatic elements

Table 3. Spearman correlation coefficients for metals found in the IVD with the division into the type of IVDD

\begin{tabular}{lcccccccc}
\hline & $\mathrm{Ag}$ & $\mathrm{As}$ & $\mathrm{Bi}$ & $\mathrm{Fe}$ & $\mathrm{Li}$ & $\mathrm{Mo}$ & $\mathrm{Se}$ & $\mathrm{Zn}$ \\
\hline Protrusion & & & & & & & & \\
\hline $\mathrm{Ag}$ & $\mathrm{X}$ & 0.05 & -0.06 & -0.06 & -0.06 & 0.01 & -0.09 & 0.04 \\
\hline $\mathrm{As}$ & 0.49 & $\mathrm{X}$ & $0.42^{*}$ & -0.20 & 0.14 & 0.25 & 0.11 & 0.23 \\
\hline $\mathrm{Bi}$ & 0.15 & 0.45 & $\mathrm{X}$ & 0.04 & -0.04 & 0.21 & $-0.48^{*}$ & 0.25 \\
\hline $\mathrm{Fe}$ & -0.37 & -0.24 & -0.16 & $\mathrm{X}$ & 0.06 & -0.22 & -0.03 & 0.07 \\
\hline $\mathrm{Li}$ & 0.41 & $0.55^{*}$ & 0.24 & -0.17 & $\mathrm{X}$ & 0.03 & -0.17 & 0.11 \\
\hline $\mathrm{Mo}$ & 0.09 & 0.23 & 0.28 & -0.09 & -0.04 & $\mathrm{X}$ & -0.08 & 0.19 \\
\hline $\mathrm{Se}$ & -0.09 & 0.12 & -0.25 & 0.38 & -0.22 & -0.36 & $\mathrm{X}$ & -0.21 \\
\hline $\mathrm{Zn}$ & 0.49 & 0.48 & 0.47 & -0.35 & 0.45 & 0.18 & -0.49 & $\mathrm{X}$ \\
\hline
\end{tabular}

Extrusion

* statistically significant 


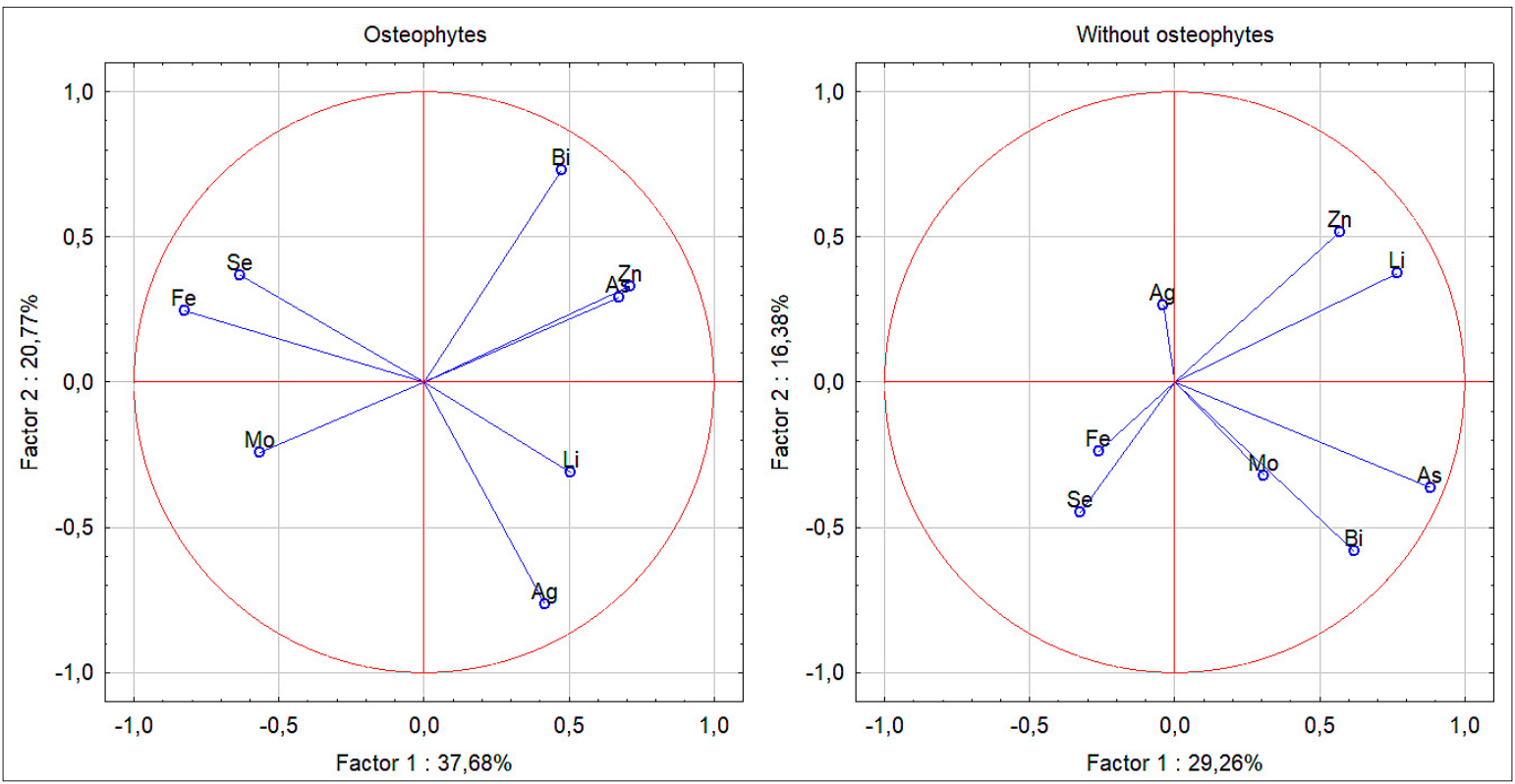

Figure 1. Analysis of principal components of element content according to the presence of osteophytes. Projection of the variables on the factor plane of the first two principal factors by osteophytes

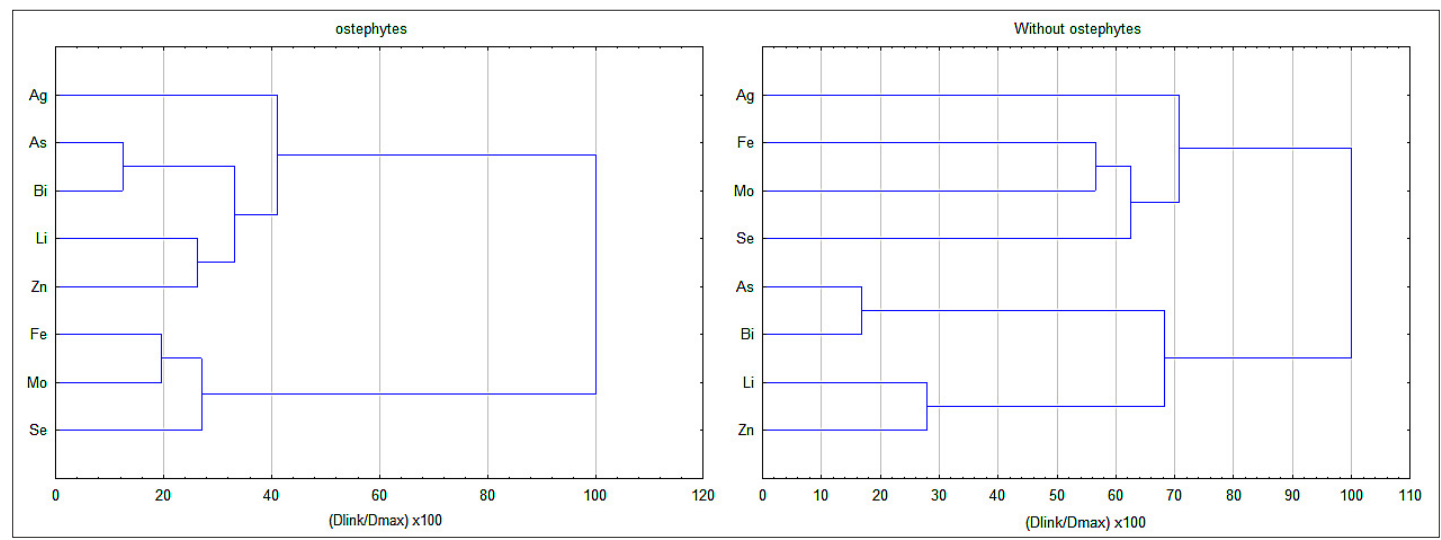

Figure 2. Cluster analysis. Dendrogram with a differentiating variable, which denotes the Pearson correlation coefficient by the Ward method for the element content in the IVD and the osteophytes

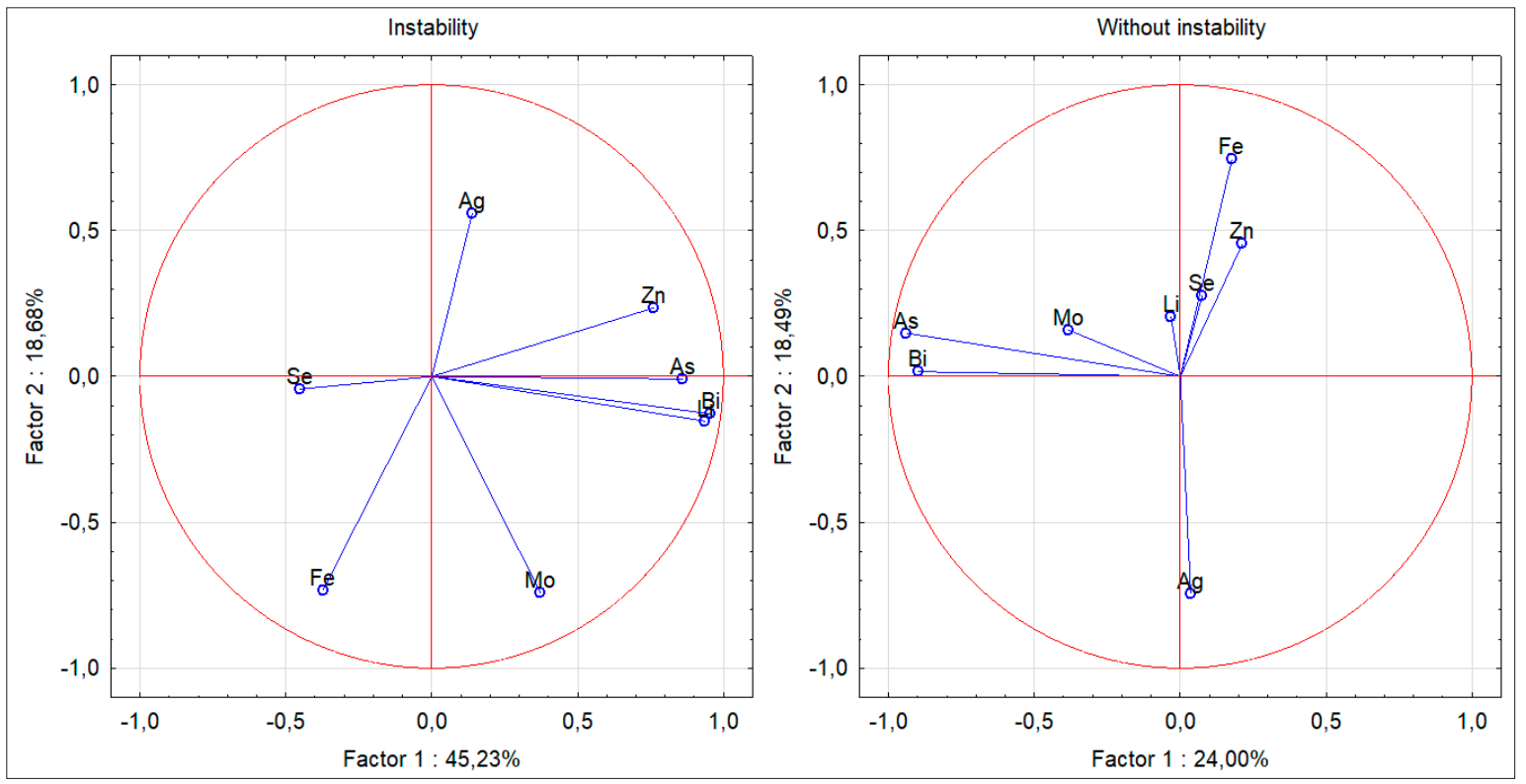

Figure 3. Principal Components Analysis of contents of elements in IVD, according to the presence of instability in the X-ray image. Projection of the variables on the factor plane of the first two principal components for presence of instability 

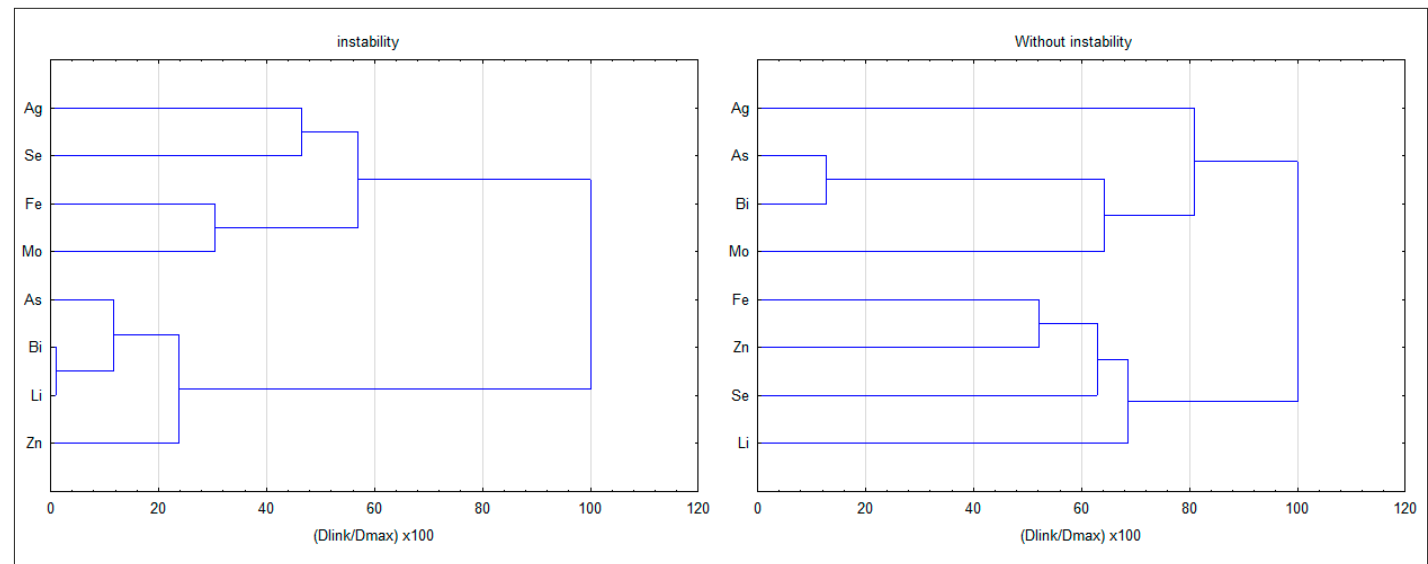

Figure 4. Cluster analysis. Dendrogram with a differentiating variable denoting the Pearson correlation coefficient by the Ward method for the content of elements in the IVD and instability.
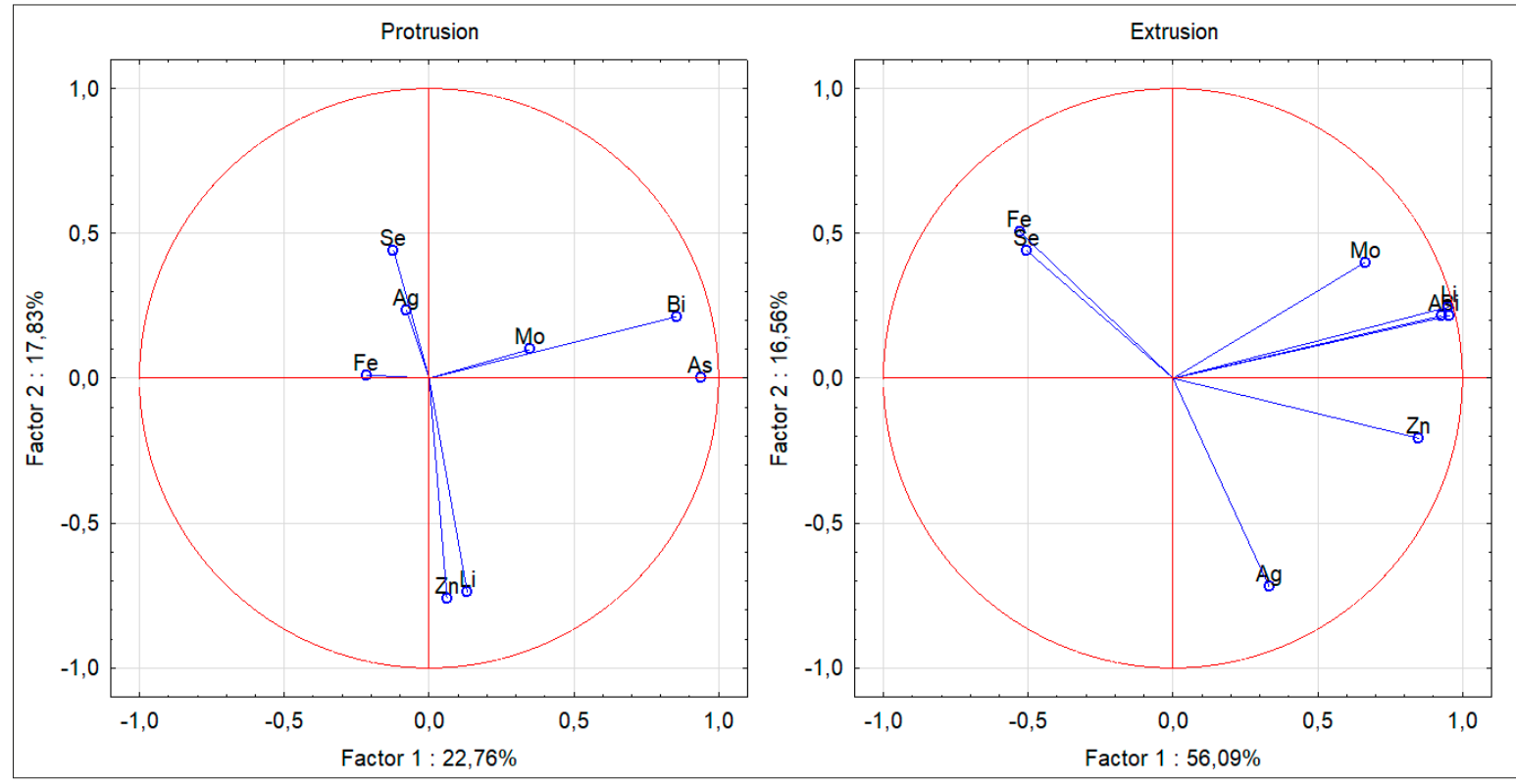

Figure 5. Principal Components Analysis of contents of elements in IVD, according to the type of deformation of annulus fibrosus. Projection of the variables on the factor plane of the first two principal components for type deformation of annulus fibrosus.

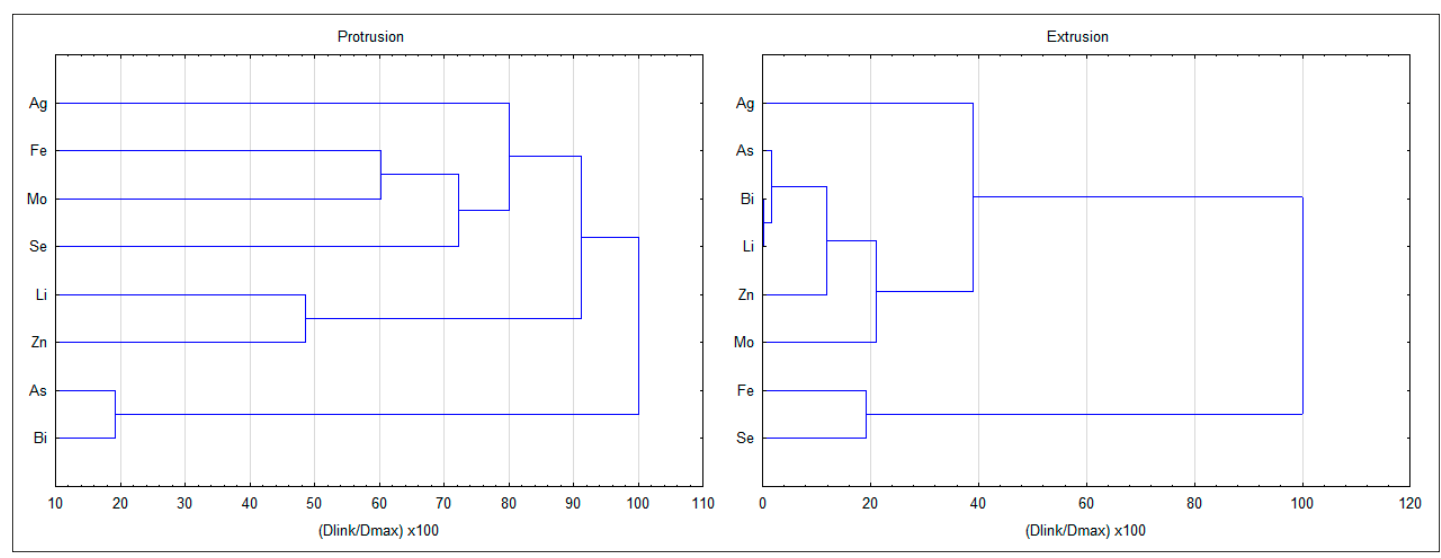

Figure 6. Cluster analysis. Dendrogram with a differentiating variable, which denotes the Pearson correlation coefficient by the Ward method for the content of elements in the IVD and type deformation of annulus fibrosus. 


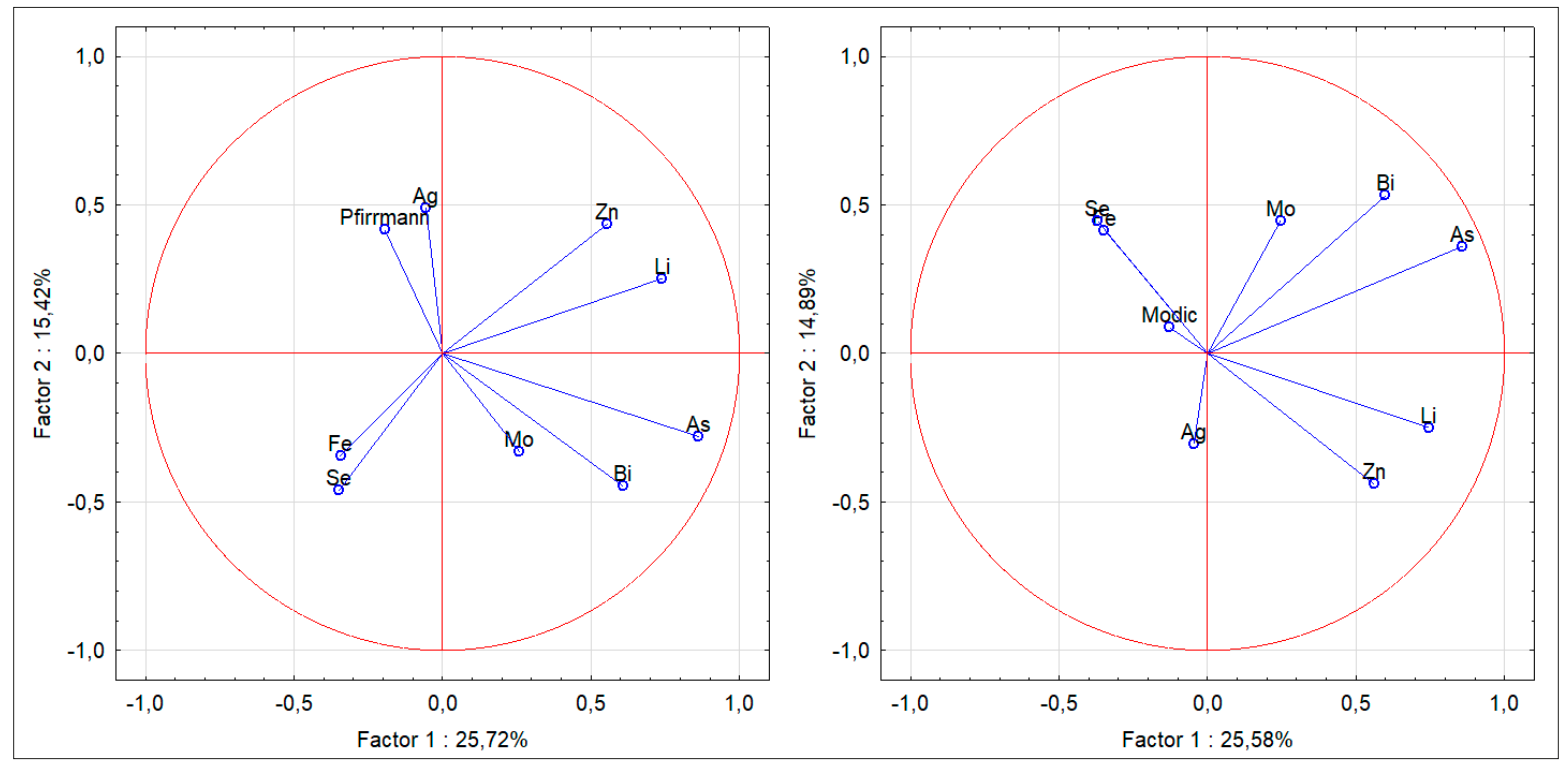

Figure 7. Principal Components Analysis of contents of elements in the IVD. Projection of the variables on the factor plane of the first two principal components for Modic and Pfirrman scale

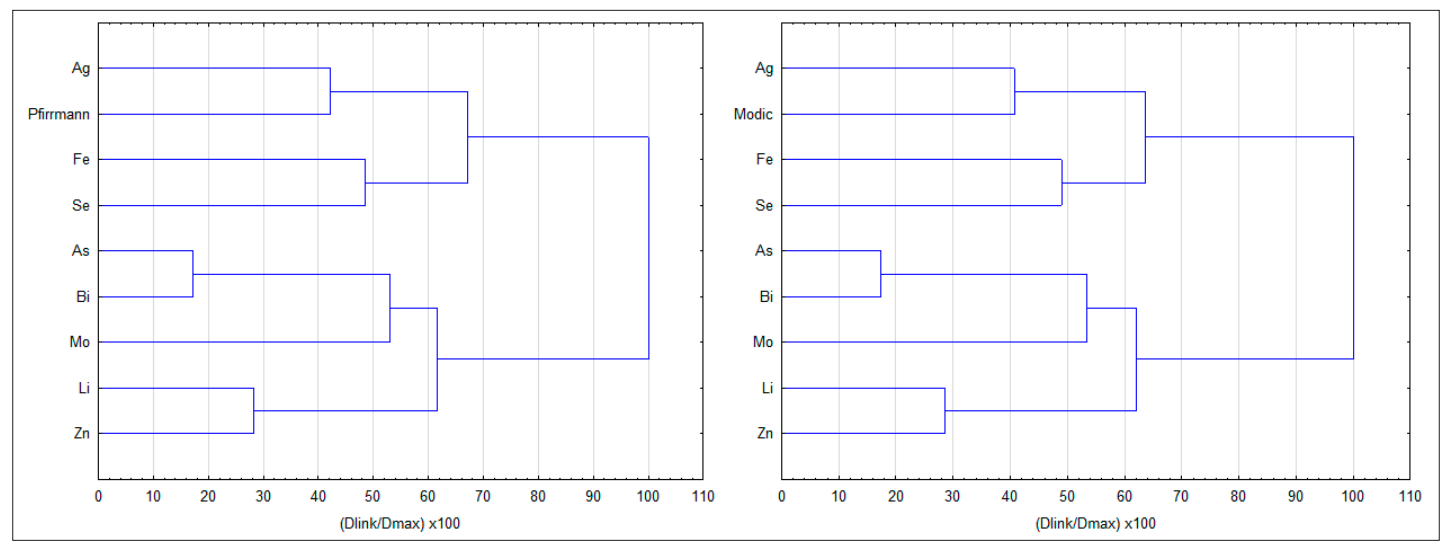

Figure 8. Cluster analysis. Dendrogram with a differentiating variable which denotes the Pearson correlation coefficient by the Ward method for the content of elements in the IVD, Modic and Pfirrman scale

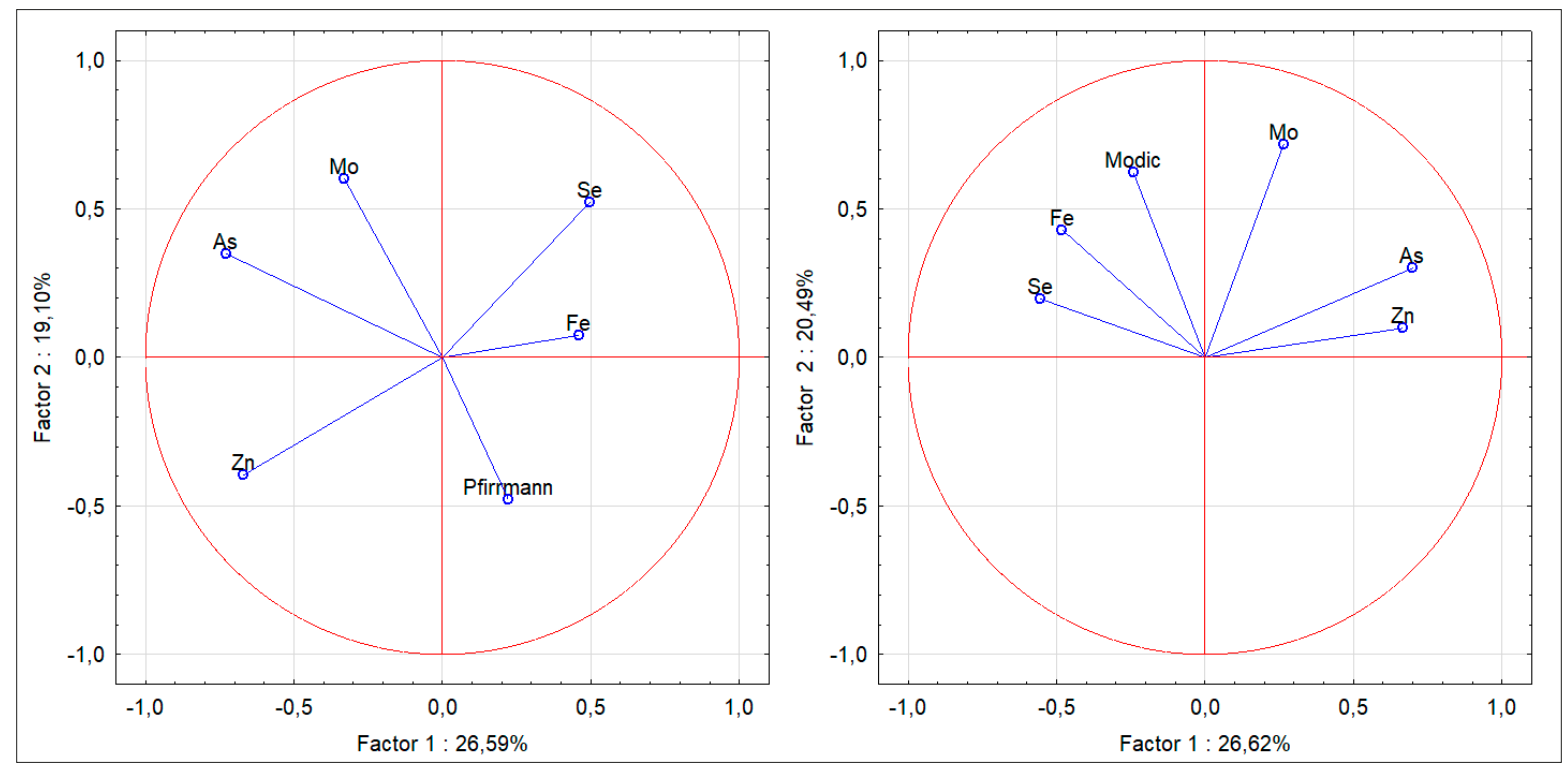

Figure 9. Principal Components Analysis of contents of oxidative elements in the IVD. Projection of variables on the factor plane of the first two principal components for Modic and Pfirrman scales 


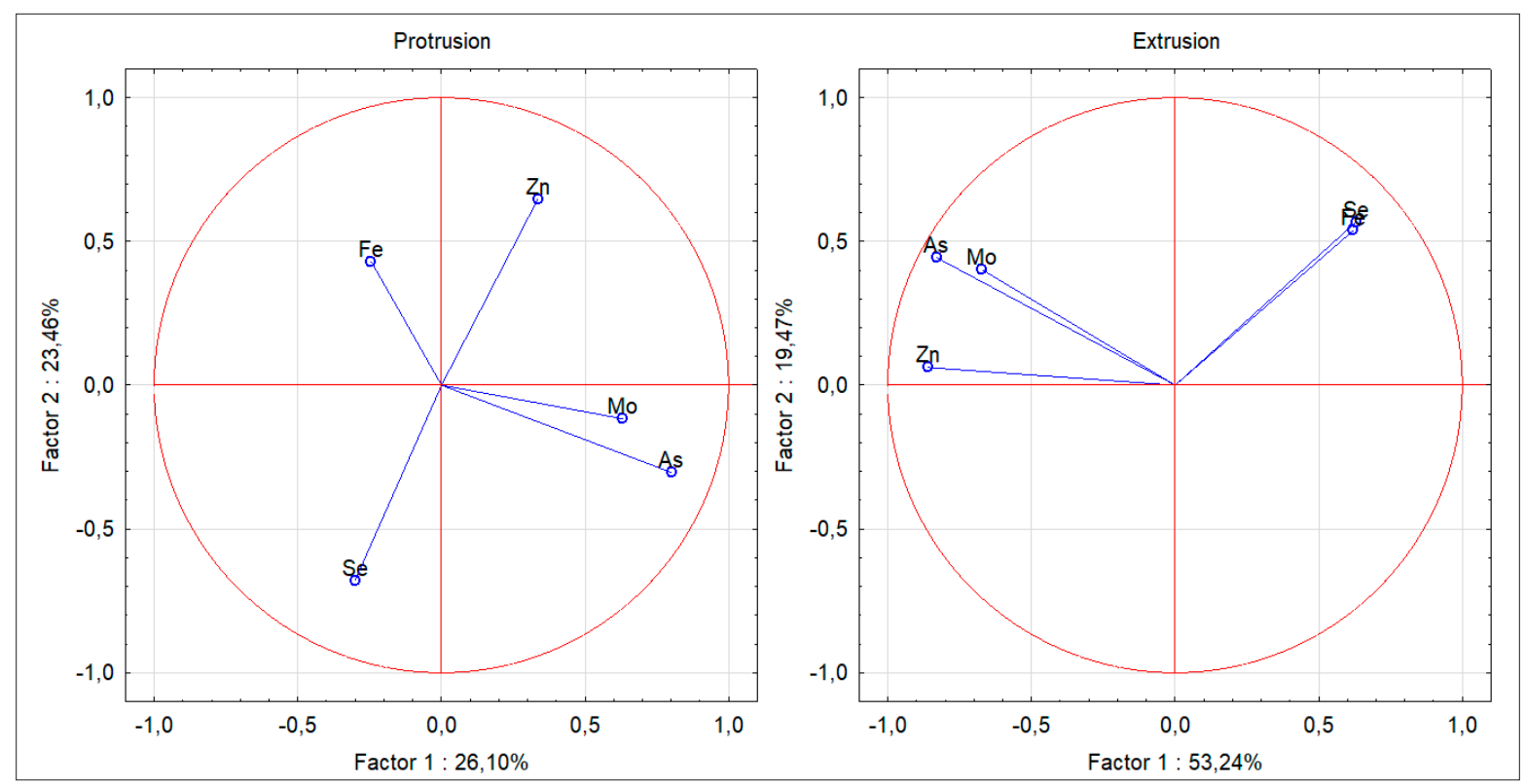

Figure 10. Principal Components Analysis of contents of enzymatic elements in IVD according to the osteophytes. Projection of the variables on the factor plane of the first two principal components for osteophytes

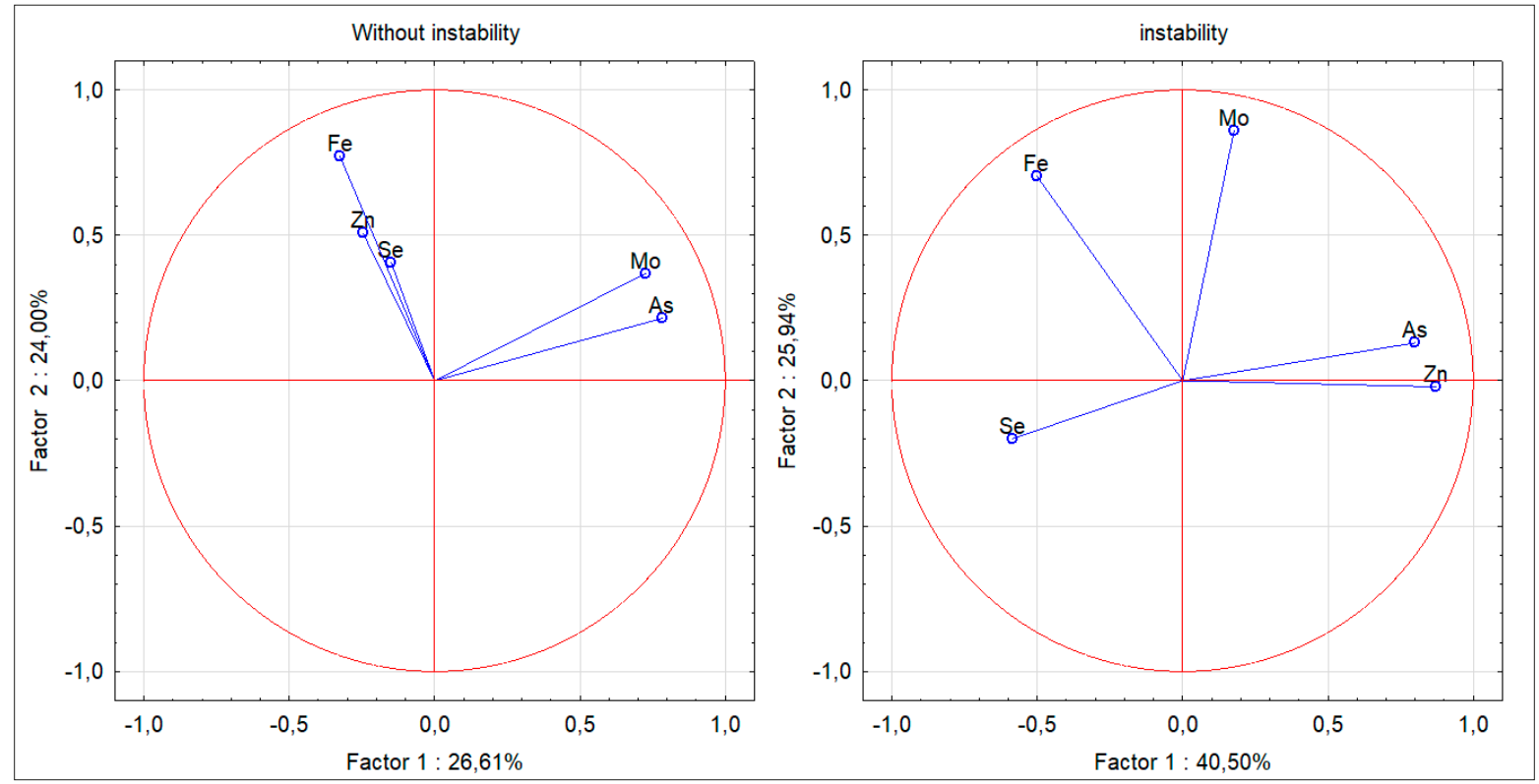

Figure 11. Principal Components Analysis of contents of oxidative elements in IVD, according to the type of deformation of annulus fibrosus. Projection of the variables on the factor plane of the first two principal components for instability

(As-Bi) (Fig. 5). In Cluster Analysis (CA), a greater similarity was shown between $\mathrm{Bi}$ and $\mathrm{Li}$ content than As (Fig. 6).

Pfirrmann and Modic scale. No correlation was demonstrated between trace elements and IVD dehydration by the Pfirrmann scale. In chemometric analysis of the first factor describing the variability of data beyond the pair of As and Bi neutral elements, the influence of $\mathrm{Zn}$ and $\mathrm{Li}$ was also confirmed as a similarity in the dendrogram. This also showed the similarity between $\mathrm{Fe}$ and Se with low oxidative and with oxidative potential, both with significant enzymatic potential. Analysis confirmed the degree of severity of the changes due to the concentration of $\mathrm{Li}(-0.41)$. The first factor was described by As-Bi, and $\mathrm{Li}$ and $\mathrm{Zn}$. Other elements and oxidative enzymes showed no significant effects on the variability observed in this analysis (Fig. 7). In clustering analysis, a higher similarity was shown between $\mathrm{Bi}-\mathrm{As}$ and Zn-Li (Fig. 8).

Oxidation potential. There was no significant correlation between the oxidation potential of the analyzed elements (Fe, $\mathrm{Zn}, \mathrm{Mo}, \mathrm{As}, \mathrm{Se}$ ) and the changes in dehydration of the IVD. The first factor was related to the content of $\mathrm{Zn}$ and As, Mo; however, it constituted only $26 \%$ of the variability observed (Fig. 9). In cluster analysis, the similarity of the Pfirrmann scale with Fe content was shown, followed by Se content. However, based on the PCA analysis, a strong relationship was found between Fe content and the osteophytes. Similar correlations between Fe and Se were found in the presence of the osteophytes. In disc herniation analysis, the 


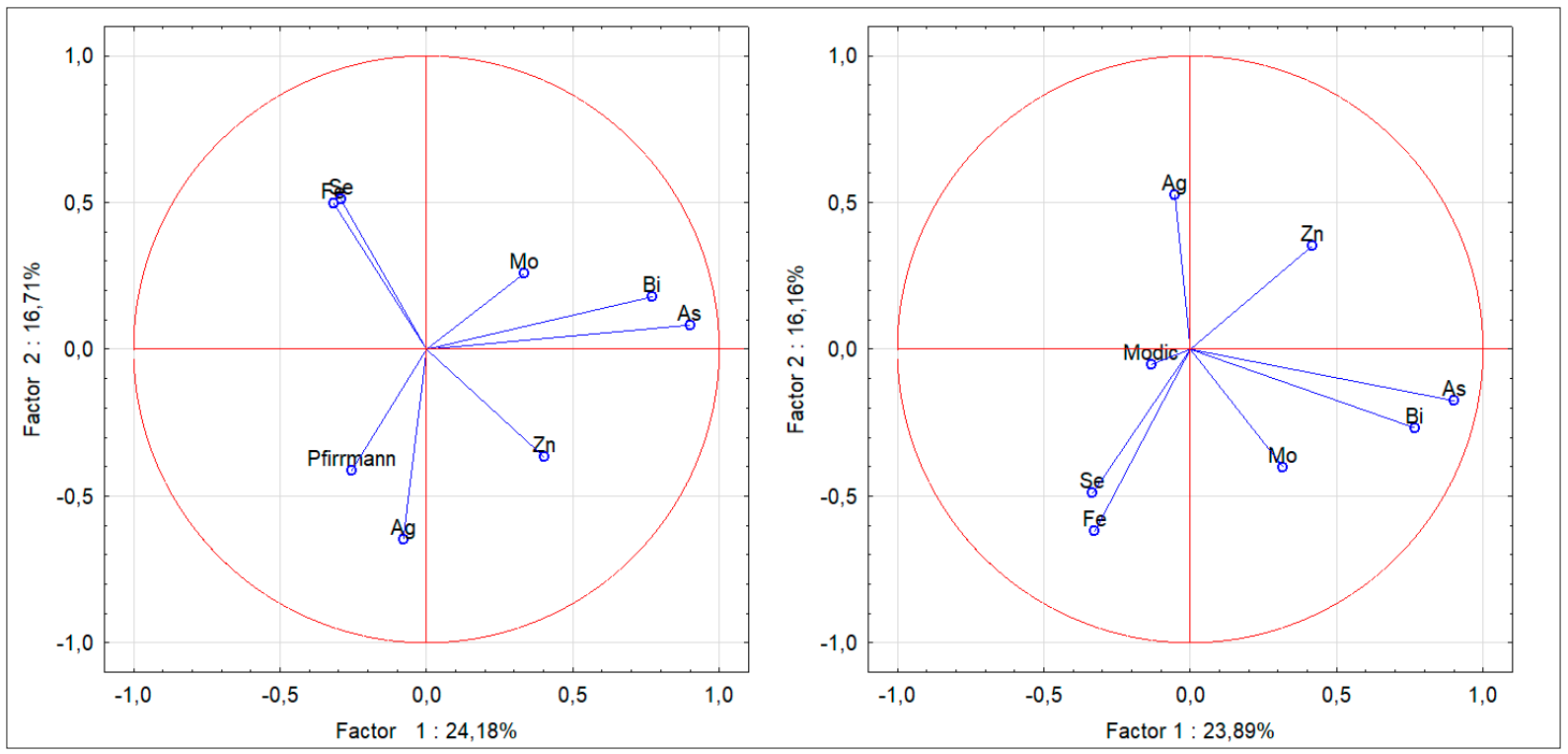

Figure 12. Principal Components Analysis of contents of enzymatic elements in the IVD. Projection of the variables on the factor plane of the first two principal components for Modic and Pfirrman scale

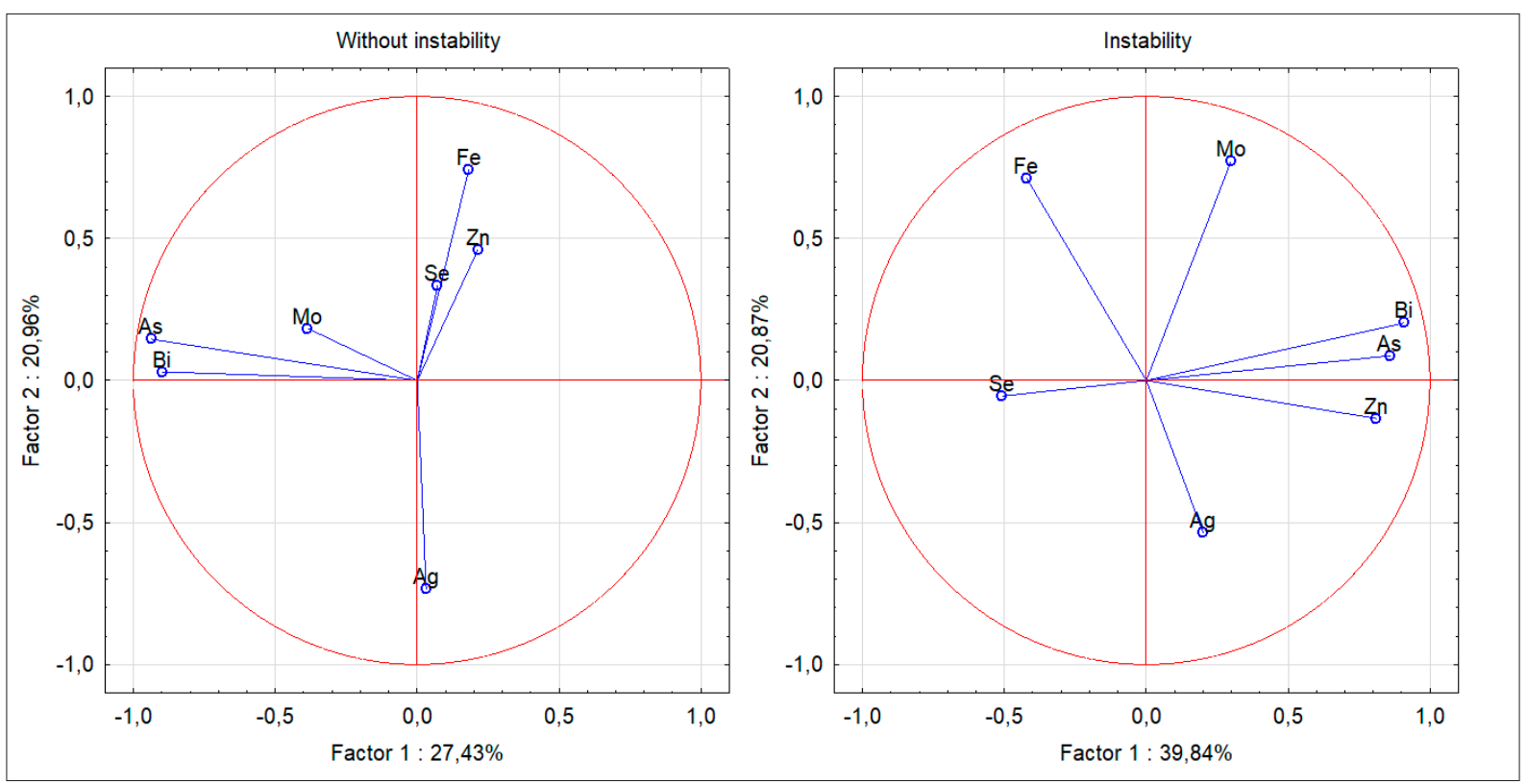

Figure 13. Principal Components Analysis of contents of enzymatic elements in IVD according to the instability. Projection of the variables on the factor plane of the first two principal components for instability

elements can be divided into two groups: As, Mo, $\mathrm{Zn}$ and Fe, Se (Fig. 10). The features of instability in the PCA indicated a high proportion of oxidative potential in almost all the elements a, with the exception of Mo. The share of the first factor was over $40 \%$ (Fig. 11).

Enzymatic potential. In the analysis of enzymatic potential in the dehydration of the IVD, a similarity was found for Fe and Se (Fig. 12). It should be underlined that the similarities were observed both in the PCA osteophytes as the only feature of the degenerative process indicating similarity with the content of Fe (Fig. S1). In chemometric analysis, there was a similarity between Ag and changes in the dehydration of the IVD. This dependence was observed in both the PCAs. In the case of deformation of the IVD, a similarity between Fe and Se was observed in the case of extrusion. The features of instability in the PCA indicated as the first group of elements: $\mathrm{Bi}-\mathrm{As}-\mathrm{Zn}$, and the second - enzymatic potential of Mo. The share of the first factor was $40 \%$ (Fig. 13).

Metals and metalloids. Taking into account the elements belonging to metals or metalloids, the main factors describing the variability were the pair of As and Bi metalloids. These elements also showed the greatest similarity. Such dependencies were observed in the analysis of the degree of IVD dehydration, changes in the subchondral bone, changes in the number of osteophytes, changes in disc herniation, and the changes in instability.

The main metal correlating with the severity of the degenerative process was $\mathrm{Fe}$ in the case of IVD dehydration and presence of the osteophytes. The correlation between Mo and Fe was also observed in the case of instability, while in 
the samples of patients in which no instability was found, Fe showed the greatest similarity with $\mathrm{Zn}$. Only in the case the Modic scale and presence of the extrusion, the similarity with the content of Mo was greater than with the remaining group of elements.

\section{DISCUSSION}

Analysis of the trace elements in IVD tissue during the degenerative processhais presented in only a few publications. Literature on trace elements in human tissue is mainly focused on bone tissue due to its active metabolism and, consequently, its ability to accumulate elements. In particular, these analyses include elements that are significantly metabolic. In addition, bone tissue is also used to assess the concentrations of toxic elements as an indicator of exposure, especially in the context of environmental pollution [6]. There have been subsequent publications in recent years which present the content of elements such as: $\mathrm{Al}, \mathrm{Cd}, \mathrm{Pb}, \mathrm{Cu}, \mathrm{Ni}, \mathrm{Mo}, \mathrm{Mg}$, and $\mathrm{Zn}$ [7] and $\mathrm{Al}, \mathrm{Cd}, \mathrm{Co}, \mathrm{Pb}, \mathrm{Cu}, \mathrm{Ni}, \mathrm{Mo}, \mathrm{Mg}, \mathrm{Zn}$ [8], and compare these elements in bone and DDD [9].

Elemental analysis, in addition to environmental exposure assessment, may be important in understanding the metabolism and typical pathological processes of the tissue under investigation. This analysis allows for the assessment of mutual relationships between elements and further searches biochemical compounds and their role in metabolic processes. Most of the elements assessed in this study except for $\mathrm{Zn}$ and Mo, have not been evaluated in human IVD tissue.

The analyzed group included patients who qualified for surgical treatment. As a consequence, the described group can characterize only to a certain extent the general group of patients with degenerative changes within the IVD. Similar to the group under study, radiological symptoms of degenerative changes in the lumbar spine are observed earliest in the L4/L5 [10]. The causes are most often seen in the local anatomy of the facet joints and the ligamental anatomy that more strongly stabilizes the L5 for the iliac bones, compared to L4 [10]

A greater content of $\mathrm{Fe}$ and Se within the IVD was found, compared to literature data, for human or animal tissue. The postulated explanation for such differences may be the dissimilarity of metabolism, specifically regarding collagen.

Available studies confirm the protective influence of Se, which inhibits proteoglycan degradation [11]. Low levels of Se may adversely affect the microstructure of the extracellular matrix of articular cartilage [12]. In addition, the cytoprotective effect of Se is also found in the degradation of collagen within the articular cartilage[13]. Se deficiencies may clinically be revealed by disorders of new bone formation, especially within the growth plate, which are related to the limited expression of proteoglycan synthesis enzymes and aggrecan-stabilizing collagen and hyaluronic acid [14]. The above analysis of the role of Se in the metabolism of morphotic elements of the IVD clearly indicates its anabolic effect in tissue metabolism.

In addition, Fe, unlike Se, has an unmistakable oxidation potential. Its increased content may indicate the inactivation of free radicals during the course of the degenerative diseases mentioned in the literature [5]. In the presented study, there was no statistically significant relationship between the Fe and Se content and the degree of intensification of radiological changes over the course of the degenerative disease. The chemometric analysis revealed a similarity in Fe content and changes mainly related to bone tissue, i.e. bone growth, as well as changes in the subchondral bone. A similarity was found between Fe and Se content in the chemometric analysis in patients with extrusion deformation and the presence of osteophytes.

Oxidative elements. Based on the analysis, the group of elements with high oxidation potential was not related to the severity of the degenerative process. In the case of spinal instability, the importance of elements with high oxidative potential in PCA has been demonstrated, but it is difficult to draw unambiguous conclusions on this basis. Instability is a distant effect of the degenerative disc process, and the associated dependence on the degenerative process itself could be regarded as a significant factor. The indicated potential relationship between free radicals and the degenerative process is mainly associated with an increase in the expression of tumour necrosis factor $\alpha$ (TNF- $\alpha$ ) and MMP-3, as well as a decrease in the expression of aggrecan encoding genes [5]. In the presented analysis, the relationship between Fe and Se, including their increased content, indicates a potentially dominant relationship with degenerative processes at the enzymatic level. This relationship was mainly observed in the analysis of deformation of the fibrous ring. The Fe content itself showed the greatest similarity with the formation of osteophytes.

$\mathrm{Fe}$ is also an important cofactor in the enzymatic hydroxylation of procollagen chains in the collagen synthesis process [15]. This process is tissue-independent and can be observed within both the soft tissue and bone tissue. In the case of bone metabolism, Fe ions are important components of heme-forming P-450 cytochromes.

Fe and Se were characterized by significant enzymatic properties, which may indicate increased activity of metabolic processes in the examined tissue over the course of the degenerative processes. These dependencies were confirmed in the chemometric analysis of the enzymatic elements, indicating a similarity in the occurrence of Se and Fe, both taking into account the displacement of the IVD and changes in the subchondral plate.

In the presence of Se ions, both an increased expression of aggrecan mRNA and a decrease in the concentration of lytic enzymes in the extracellular matrix were observed. In addition, deficiency of Se adversely affects the type II collagen and annulus fibrosus [13]. Se deficiencies are also associated with changes that are characteristic of the degenerative process or bone changes that occur over the course of systemic diseases [16]. The observed consequences of Se deficiency in bone tissue were mainly related to the formation of collagen type II, and increased expression of enzymes responsible for catabolism of the extracellular matrix. The direct relationship between bone effusion and Fe content confirms the effect of the element on bone tissue metabolism [14].

Enzymatic elements. An important result is chemometric analysis indicating the similarity of Ag content with the degenerative processes is the dehydration of the IVD and changes in the subchondral bone. In the literature, incidental reports indicate that $\mathrm{Ag}$ may promote repair processes in increased expression of proteoglycans and collagen [17]; 
such changes have been observed in the regeneration of tendons. Unfortunately, the available literature does not describe any links between the degenerative process and the Ag content. A negative correlation between Fe and Ag content may indirectly indicate that the potential effects of Ag may be more related to the IVD tissue than the adjacent bone tissue over the course of the degenerative changes. The effect of $\mathrm{Ag}$ is antagonistic to the Fe content.

In biological processes, the usefulness of group 15 metalloids in the methylation process has been demonstrated as a process of detoxification of bacteria. It is possible that methylation is also possible within mammalian tissues, and that it leads to a complete reduction in toxicity, in particular, a reduction in As content.

The biological features of As in particular indicate its toxic effect when expressing genes important in the production of collagen, as well as disorders in the small blood vessels [18, 19]. Bi, apart from its use as a component of antacids, has an inhibitory effect on the development of some bacteria that are typically found in the gastrointestinal tract, and it has toxic effects when in high doses. The metabolic role of $\mathrm{Bi}$, as mentioned, has not been defined. Bi is an effective antidote for the adverse effects of As, mentioned above [20]. The protective role of Bi begins 24 hours after its administration. At the same time, this element reduces the accumulation of As in tissues. Primary deposition of As can affect the degenerative process through abnormalities in extracellular matrix synthesis. Bi deposition can be a secondary mechanism, depending on the level of As content, eliminating its detrimental effect. The most probable explanation for the observed relationship between the coexistence of $\mathrm{As}$ and $\mathrm{Bi}$ is the elimination of toxic As through binding to Bi compounds in the mechanisms described above.

Metals and metalloids. Analysis showed that metals and metalloids are not connected with the severity of the degenerative process within the IVD. The first factor describing metalloids, $\mathrm{As}, \mathrm{Bi}$, and the metal Fe, was similar to the severity of the degenerative process in the presence of osteophytes. This dependence confirms the important role of Fe in the collagen synthesis process, as mentioned previously [14]. The obtained results suggest that the elevated Fe level should be more related to the repair processes within the IVD rather than the processes of increased catabolism of the disc tissue. In the analysis of the available literature, no study was found to confirm the influence of $\mathrm{Fe}$ or its compounds on the degeneration of the IVD.

In the analysis of the severity of degenerative changes in the subchondral bone and extrusion, the similarity in Fe and Mo content was higher than with the remaining group of elements. The relationship between Mo and Fe was also observed in the case of instability. In cases where no instability was found, Fe showed the greatest similarity with $\mathrm{Zn}$. In the literature, enzymatic Fe and Mo compounds have been confirmed in function of the Mo cofactor (Mo cofactor, Moco) consists of pterin (photolyase) and Mo [21]. The similarity in the occurrence of Mo and Fe shown in this study may indicate its broad biological significance in the connective tissue of the IVD. In the case of collagen, Mo may cause disturbances in the formation of crosslinks. This element can be combined with collagen fibres, especially at potential cross-linking sites. The effect of combining collagen fibers with Mo may be disturbances in the collagen synthesis process [21]. Mo is an essential trace element in humans, included in the metabolism of sulfur-containing amino acids, although it is difficult to assign an explicit role in the metabolism of the disc, and in the degenerative processes [21].

The presented dependences suggest the importance of enzymatic processes and their associated elements in the intensification of morphological changes, including bone tissue over the course of DDD.

There are no studies in the literature confirming the impact of Li on the metabolism of both collagen and proteoglycans. The current study demonstrates a negative correlation between Li content and subchondral bone changes. This corroborates the literature reports presented above regarding both the quality of fibres and contribution of the element in the inhibition of catabolic processes in the extracellular matrix by reducing the activity of metalloproteinases, leading to the recognition of its role in the metabolic processes of the IVD. Recent reports have also confirmed the other protective mechanism of Li in the nervous tissue. The presented research and literature reports indicate the need for further studies on the role of $\mathrm{Li}$ in IVD metabolism and degenerative processes. The Li content (the only one of the analyzed elements) showed a direct correlation between $\mathrm{Li}$ and changes in the subchondral girth, evaluated according to the Modic scale.

\section{CONCLUSIONS}

The analysis indicated the enzymatic similarity of Fe and Se in the group of patients with DDD.

There was a negative correlation between Li concentration and the degree of advancement of bone changes in the subarticular marginal plate. With the exception of $\mathrm{Li}$ concentration, there was no direct correlation between the content of the other elements and the severity of the osteoarthritis symptoms during radiological examination.

Ag content correlated with degenerative process: dehydration of the IVD and changes in subchondral bone. A potential relationship between a pair of non-enzymatic elements and metalloids (As and Bi in the degeneration of the IVD) was demonstrated.

The presented relationships indicate new directions for further research on the IVD degeneration process.

\section{Acknowledgements}

Funding source. National Science Center in Poland (MINIATURA 1 2017), under grant agreement no. DEC2017/01/X/NZ5/00308.

\section{REFERENCES}

1. Binch AL, Cole AA, Breakwell LM, et al. Nerves are more abundant than blood vessels in the degenerate human intervertebral disc. Arthritis Res Ther. 2015; 17(1): 370.

2. Gilbert HTJ, Hodson N, Baird P, Richardson SM, Hoyland JA. Acidic pH promotes intervertebral disc degeneration: Acid-sensing ion channel -3 as a potential therapeutic target. Sci Rep. 2016; 6: 37360.

3. Wu Y, Cisewski S, Sachs BL, Yao H. Effect of cartilage endplate on cell based disc regeneration: a finite element analysis. Mol Cell Biomech. 2013; 10(2): 159-82.

4. Le Maitre CL, Richardson SM, Baird P, Freemont AJ, Hoyland JA. Expression of receptors for putative anabolic growth factors in human intervertebral disc: implications for repair and regeneration of the disc. J Pathol. 2005; 207(4): 445-52. 
5. Suzuki S, Fujita N, Hosogane N, et al. Excessive reactive oxygen species are therapeutic targets for intervertebral disc degeneration. Arthritis Res Ther. 2015; 17(1): 316.

6. Zioła-Frankowska A, Kubaszewski Ł, Dąbrowski M, et al. The content of the 14 metals in cancellous and cortical bone of the hip joint affected by osteoarthritis. BioMed Res Int. 2015; 2015.

7. Kubaszewski Ł, Zioła-Frankowska A, Frankowski M, et al. Atomic absorption spectrometry analysis of trace elements in degenerated intervertebral disc tissue. Med Sci Monitor: Int Med J Exp Clin Res. 2014; $20: 2157$.

8. Nowakowski A, Kubaszewski L, Frankowski M, et al. Analysis of trace element in intervertebral disc by atomic absorption spectrometry techniques in degenerative disc disease in the Polish population. Ann Agric Environ Med. 2015; 22(2).

9. Kubaszewski Ł, Zioła-Frankowska A, Frankowski M, et al. Comparison of trace element concentration in bone and intervertebral disc tissue by atomic absorption spectrometry techniques. J Orthopaedic Surg Res. 2014; 9(1): 99

10. Saleem S, Aslam HM, Rehmani MA, Raees A, Alvi AA, Ashraf J. Lumbar disc degenerative disease: disc degeneration symptoms and magnetic resonance image findings. Asian Spine J. 2013; 7(4): 322-34.

11. Li SY, Cao JL, Shi ZL, et al. Promotion of the articular cartilage proteoglycan degradation by $\mathrm{T}-2$ toxin and selenium protective effect. J Zhejiang Univ Sci B. 2008; 9(1): 22-33.

12. Yasuda S, Yasuda T, Liu MY, et al. Sulfation of chlorotyrosine and nitrotyrosine by human lung endothelial and epithelial cells: role of the human SULT1A3. Toxicol Appl Pharmacol. 2011; 251(2): 104-9.
13. Lu M, Cao J, Liu F, et al. The effects of mycotoxins and selenium deficiency on tissue-engineered cartilage. Cells Tissues Organs. 2012; 196(3): 241-50.

14. Medeiros DM. Copper, iron, and selenium dietary deficiencies negatively impact skeletal integrity: A review. Exp Biol Med. 2016; 241(12): 1316-22.

15. Toxqui L, Vaquero M. Chronic iron deficiency as an emerging risk factor for osteoporosis: a hypothesis. Nutrients. 2015; 7(4): 2324-44.

16. Min Z, Zhao W, Zhong N, et al. Abnormality of epiphyseal plate induced by selenium deficiency diet in two generation DA rats. APMIS. 2015; 123(8): 697-705.

17. Kwan KH, Yeung KW, Liu X, et al. Silver nanoparticles alter proteoglycan expression in the promotion of tendon repair. Nanomedicine: Nanotechnol Biol Med. 2014; 10(7): 1375-83.

18. Hays AM, Lantz RC, Rodgers LS, et al. Arsenic-induced decreases in the vascular matrix. Toxicol Pathol. 2008; 36(6): 805-17.

19. Rade M, Määttä JH, Freidin MB, Airaksinen O, Karppinen J, Williams FM. Vertebral Endplate Defect as Initiating Factor in Intervertebral Disc Degeneration. Spine. 2018; 43(6): 412-9.

20. Fujiwara Y, Yamamoto C, Inagaki T, Satoh M, Kaji T. Bismuth protects against arsenite-induced inhibition of proteoglycan synthesis in cultured vascular endothelial cells. J Toxicol Sci. 2012; 37(4): 837-43.

21. Mendel RR. Metabolism of molybdenum. Met Ions Life Sci. 2013; 12 : 503-28. 